\title{
EVALUATING THE EFFECTS OF HIGH LIQUID VISCOSITY AND FLOW VARIABLES ON HORIZONTAL OIL-GAS SLUG FLOWS BY GAMMA RADIATION METHOD
}

\author{
C.N. OKEZUE \\ The School of Engineering, University of Hull, UK.
}

\begin{abstract}
Hydrodynamic slug flow is the commonest flow regime observed in high viscosity liquid-gas horizontal pipelines over a wide range of different flow conditions. Hydrodynamic slugging tends to generate large vibrations that may impose structural instability or even damage oil production pipelines. For that reason, there is a need to investigate high viscosity slug flow regime to understand its complex characteristics. This is pertinent when considering that existing slug flow models used in the petroleum industry to design production pipelines are not suitable for predicting the behaviour of high viscosity oil-gas flow. In this study, the effects of liquid viscosity and flow variables on slug flow regime were investigated experimentally through the analysis of two key parameters-slug frequency and slug body liquid holdup, both measured with a gamma densitometer. Comparison of the measured slug parameters to existing correlations revealed that slug body liquid holdup correlations were in close agreement with high viscosity experimental data. However, none of the existing slug frequency correlations used was able to produce accurate predictions. A new empirical correlation for slug frequency was proposed. Compared with existing correlations, the newly proposed correlation performed much better in predicting slug frequency of high viscosity liquid-gas flows.

Keywords: Empirical correlation, gamma beam densitometer, hydrodynamic slug flow regime, multiplelinear regression, slug body liquid holdup, slug frequency, two-phase flow.
\end{abstract}

\section{INTRODUCTION}

Previous experimental studies on high viscosity liquid-gas horizontal flows have identified hydrodynamic slug flow as the commonest flow regime encountered over a wide range of different flow conditions [1-3]. Unfortunately, mechanistic models currently used for designing and analysing the performance of oil production pipelines and their support systems are not suitable for simulating the characteristics of high viscosity oil-gas systems. This is because the empirical correlations used to close the governing equations of these mechanistic models are based on test data of low viscosity oil-gas flows, which tend to have different hydrodynamic features compared with high viscosity liquid-gas flows.

Gregory and Scott [4] were among the earliest researchers to formulate an empirical model for predicting slug frequency in horizontal gas-liquid flows. The empirical model correlates mixture velocity, diameter and gravitational acceleration and ignores the physical properties of the multiphase working fluid involved. The authors developed the correlation on the basis of experimental observations of multiphase mixture of carbon dioxide and water flowing in horizontal pipes with internal diameters of 19 and $35 \mathrm{~mm}$.

Gregory et al. [5] developed one of the commonly used empirical correlations for predicting slug body liquid holdup. The correlation was based on capacitance sensor measurements of in situ liquid volume fraction of liquid slugs flowing inside gas-liquid horizontal pipelines with internal pipe diameters of 25.8 and $51.2 \mathrm{~mm}$. The oil used throughout the oil air tests had a low viscosity of $0.00675 \mathrm{~kg} / \mathrm{m} . \mathrm{s}(6.75 \mathrm{cP})$.

Heywood and Richardson [6] performed air-water experiments inside a pipe with a 42-mm bore. They used gamma densitometry to capture radiation intensity data, which were used to 
generate probability density function plots of the liquid hold-up for the slug flow. The average liquid hold-up within the film region and average liquid hold-up within the slug body were obtained from these functions. The authors estimated their experimental slug frequency from power spectral density (PSD) plots. They developed an empirical model correlating average slug frequency with mixture velocity, input gas volume fraction and the Froude number. Heywood and Richardson [6] model is similar to the Gregory and Scott [4] correlation, but is based on a relatively smaller experimental data set.

Manolis et al. [7] experimentally investigated the relationship between pressure and slug frequency. The authors modified the Gregory and Scott [4] correlation for the purposes of analysing high-pressure flow systems. Although the Manolis et al. [7] correlation produced more accurate predictions than the original Gregory and Scott [4] correlation, it was also found that the pressure had little effect on slug frequency.

Nydal [8] developed a slug frequency correlation on the basis of air-water flow experiments performed in pipes with internal diameter ranging from 31 to $90 \mathrm{~mm}$. The model correlates the pipe diameter, gravitational acceleration and superficial liquid velocity with the slug frequency. Since gas velocity is neglected, the Nydal [8] correlation can only be expected to give reasonable predictions in low viscosity liquid-gas flow systems where the liquid flow rate is so high that gas velocity has negligible impact on slug frequency.

Abdul-Majeed [9] and Gomez et al. [10] proposed unified empirical correlations for calculating slug body liquid holdup for different pipe orientations. Abdul-Majeed [9] correlation is capable of predicting slug body liquid holdup in both horizontal and inclined liquid-gas pipe flow. The correlation was developed from a large database of oil-gas experiments conducted in pipes with internal diameters of 25.8 and $203.2 \mathrm{~mm}$ for liquid viscosity ranging from 0.001 $\mathrm{kg} / \mathrm{ms}(1.0 \mathrm{cP})$ to $0.007 \mathrm{~kg} / \mathrm{ms}(7.0 \mathrm{cP})$. On the other hand, Gomez et al. [10] used experimental data from six different slug flow studies in literature to develop their own unified correlation for predicting slug body liquid holdup in vertical, horizontal and inclined gasliquid pipe flow.

Shea et al. [11] developed a slug frequency correlation based purely on data from an oil field. It was the first correlation to make slug frequency a function of pipe length. In addition to pipe length, the slug frequency correlation is also a function of pipe diameter and superficial liquid velocity.

Gokcal et al. [12] based their work on observations made from high viscosity oil-air flow experiments in a horizontal pipe with $50.8-\mathrm{mm}$ bore. The oil viscosities used in the experiments were restricted to the range of $0.181 \mathrm{~kg} / \mathrm{ms}(181 \mathrm{cP})$ to $0.589 \mathrm{~kg} / \mathrm{ms}(589 \mathrm{cP})$. Gokcal et al. [12] developed a slug frequency correlation that took explicit account of the effects of liquid viscosity by balancing viscous and gravitational forces acting on the slug flow. Kora et al. [13] investigated the effect of high liquid viscosity on slug body liquid holdup. The oil-gas experimental study was conducted in a horizontal pipe section with internal diameter of $50.8 \mathrm{~mm}$ for the liquid viscosity range of $0.181 \mathrm{~kg} / \mathrm{ms}(181 \mathrm{cP})$ to $0.589 \mathrm{~kg} / \mathrm{ms}(589 \mathrm{cP})$. The authors did not observe any significant liquid viscosity effect on slug liquid holdup. On the basis of their study, Kora et al. [13] developed an empirical model to predict slug body liquid holdup.

Although few studies such as Gokcal et al. [12] and Kora et al. [13] developed correlations for the prediction of high viscosity slug parameters, the fact remains that they are based on oil-gas test data with liquid viscosities much lower than the $1.1 \mathrm{~kg} / \mathrm{ms}-4.0 \mathrm{~kg} / \mathrm{ms}$ range under investigation in this paper. In this research paper, an attempt is made to close the knowledge gap through the experimental investigation of the effect of high liquid viscosity on key slug parameters for the liquid range of $1.1 \mathrm{~kg} / \mathrm{ms}(1100 \mathrm{cP})$ to $4.0 \mathrm{~kg} / \mathrm{ms}(4000 \mathrm{cP})$. The effects of flow variables on the high viscosity slug flow were examined as well 


\section{EXPERIMENTAL SYSTEM}

\subsection{Layout of test facility}

All experiments were performed in the 3-inch. 'Cold Heavy Oil Production with Sand' (CHOPS) test rig at Cranfield University. As depicted in Fig. 1, the test rig includes a horizontal multiphase flow test section and supply systems for compressed air, water, light oil and heavy oil. The horizontal test section consists of transparent Perspex pipes (74.2-mm bores) and steel pipes (73.2-mm bore) joined together by their end flanges.

Oil-air two-phase flow experiments are not the only tests performed in the CHOPS test rig. As the name of the test rig suggests, high viscosity oil-sand-water three-phase flow experiments are also carried out. A detailed description of the test rig was provided in Okezue [14].

\subsection{Instrumentation}

As illustrated in Fig. 2, the fixed single-beam gamma densitometer manufactured by Neftemer Ltd consists of a gamma source block and a sodium iodide (NaI) scintillation radiation detector.

The gamma source block contains a 5.5-GBq Caesium-137 radioisotope housed within a lead radiation protection shield, which in turn, is encased in stainless steel. The caesium-137

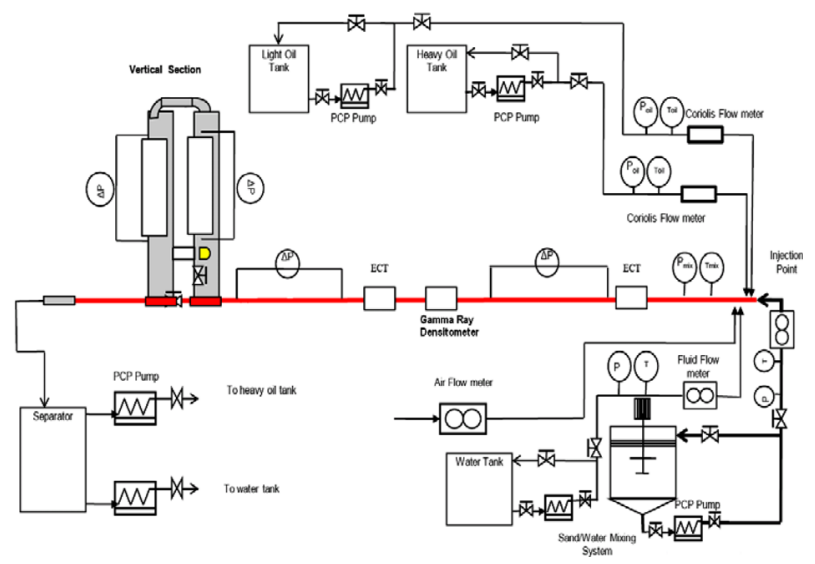

Figure 1: A schematic diagram of the 3-inch. CHOPS test rig.

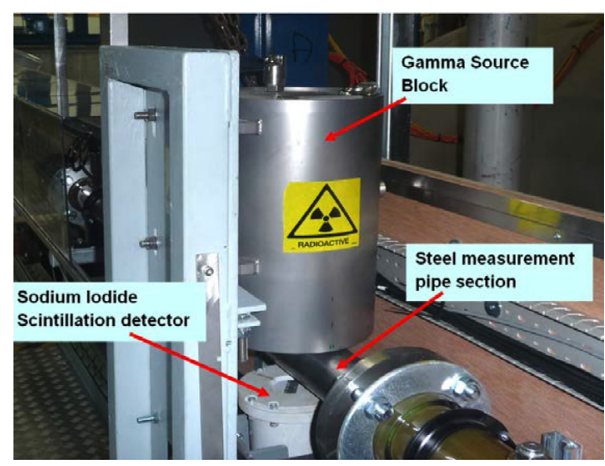

Figure 2: The gamma ray densitometer in the 3-inch. CHOPS test rig. 
radioisotope in the Neftemer densitometer is a dual-energy source emitting gamma rays in two broad photon energy levels. The transmitted gamma radiation is the source of the $662-\mathrm{keV}$ high-energy level while scattered gamma radiation is the source of the lower energy level range of $100-300 \mathrm{keV}$.

The sodium iodide (NaI) scintillation radiation detector is used to measure two separate sets of gamma attenuation data for the high- and low-energy levels at the sampling rate of $250 \mathrm{~Hz}$. For this experimental work, only the measured gamma attenuation data for the high-energy spectrum was used in estimating slug frequency and slug body liquid holdup.

Due to the random nature of gamma photon emissions from the caesium-137, there is a statistical uncertainty in gamma beam measurements.

This uncertainty is inversely proportional to the measurement time. In other words, statistical uncertainty decreases as the measurement time is increased and can be described by the equation:

$$
\text { Statistical uncertainty }=\frac{1}{\operatorname{Sen} \sqrt{N_{\text {count }}}}
$$

Statistical uncertainty is dependent on the sensitivity (Sen) of the densitometer and the size of the gamma attenuation data $\left(N_{\text {count }}\right)$ measured for a gas-liquid mixture over a period of time. Sensitivity is the relative difference between the response of the gamma densitometer to pure liquid and to pure gas:

$$
\operatorname{Sensitivity~}(\operatorname{Sen})=\frac{I_{G}-I_{L}}{0.5\left(I_{G}+I_{L}\right)}
$$

' $I_{G}$ ' and ' $I_{L}$ ' in the above equation represent mean gamma count values obtained when the gamma beam densitometer was calibrated with $100 \%$ air and $100 \%$ oil, respectively. In this present study, the gamma attenuation data were recorded for an average measurement time of 70 s per experimental run, giving an average statistical uncertainty of $1.70 \%$.

Apart from statistical uncertainty due to random gamma photon emissions, there are other sources of error in gamma beam measurements. These are as follows: systematic error in the sodium iodide (NaI) scintillation radiation detector and error due to dynamic fluctuation of the gas-liquid two-phase flow field in the measurement pipe section. Error bars have been added to Figs 9-12 to account for the effect of all sources of error in measurements performed with the gamma densitometer.

\subsection{Test flow conditions}

A series of experiments were performed with the CHOPS rig using the highly viscous CYL680 oil and compressed air as test fluids. Table 1 summarizes the range of operating conditions covered.

Table 1: Fluid properties and flow conditions of horizontal oil-air flow.

\begin{tabular}{lllll}
\hline Test fluid & Density $\left(\mathrm{kg} / \mathrm{m}^{3}\right)$ & $\begin{array}{l}\text { Superficial } \\
\text { velocity }(\mathrm{m} / \mathrm{s})\end{array}$ & $\begin{array}{l}\text { Dynamic } \\
\text { viscosity }(\mathrm{kg} / \mathrm{ms})\end{array}$ & $\begin{array}{l}\text { Surface } \\
\text { tension }(\mathrm{N} / \mathrm{m})\end{array}$ \\
\hline Air & 1.22 & $\mathrm{~V}_{\mathrm{sg}}=0.00-4.00$ & 0.0000183 & - \\
Oil & 900.32 & $\mathrm{~V}_{\text {so }}=0.06-0.20$ & $1.10-4.00$ & 0.0313 \\
\hline
\end{tabular}




\subsection{Test procedure}

The procedure for carrying out oil-air tests in the 3-inch. CHOPS rig starts with initial introduction of single-phase viscous oil into the horizontal multiphase flow test pipe section. The liquid superficial velocity $\left(V_{\mathrm{so}}\right)$ is controlled by adjusting by-pass valve on the test rig or altering the speed of the oil pump. The liquid flow is usually given a few minutes to stabilize before compressed air is introduced into the horizontal test section. The air superficial velocity $\left(V_{\mathrm{sg}}\right)$ is controlled by means of a control valve in the test rig. For each experimental run, the oil-air mixture is allowed a few minutes to stabilize so that the prevailing flow regime inside the horizontal pipe test section is fully developed. Once the multiphase flow is stable, the fixed single-beam gamma densitometer is used to measure or estimate the key slug parameters. The experimental procedure described above was repeated for oil with average dynamic viscosities $\left(\mu_{L}\right)$ of $1.1,3.4$ and $4.0 \mathrm{~kg} / \mathrm{ms}$. Average dynamic viscosity is used as a parameter in this study because no single constant value of dynamic viscosity can fully characterize the viscous effect of CYL-680 oil, which slightly behaves like a non-Newtonian fluid. In this study, the deviation of instantaneous dynamic viscosities from their average values was found to be minor.

\section{ANALYSIS AND DISCUSSION OF EXPERIMENTAL RESULTS}

\subsection{Effect of flow variables and viscosity on slug frequency}

From the measured gamma attenuation data, liquid holdup data were calculated and then plotted as a function of time to create time-series diagrams. As shown in Fig. 3, the peaks in the signal waveforms of the time-series graph are indicative of the passage of liquid slug bodies through the steel measurement pipe section of the gamma densitometer, whereas the troughs indicate the passage of the film region. Slug frequency is estimated by counting the number of peaks and then dividing it by the measurement time. However, not all liquid holdup time series graphs are as perfect as Fig. 3. There are time series diagrams where the peaks are of different heights with some representing the passage of slug bodies and other merely representing travelling waves.

To isolate travelling waves from slug bodies, a liquid holdup threshold value of 0.7 recommended by Nydal [8] is adopted as shown in Fig. 3. In estimating the slug frequency, only peaks above the liquid holdup threshold value were counted as slug bodies. Peaks below the threshold were considered travelling waves and ignored. Slug frequency was plotted against superficial air velocity for different liquid velocities and three oil viscosities namely - 1.1, 3.4 and $4.0 \mathrm{~kg} / \mathrm{ms}$. The effect of liquid viscosity and flow variables on slug frequency at different viscosities was examined in Fig. 4.

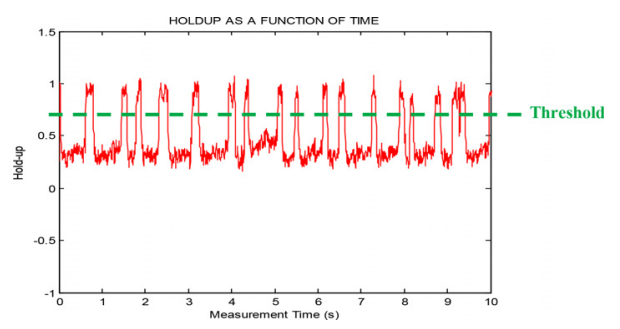

Figure 3: The threshold value in the time series is used to estimate slug frequency. 


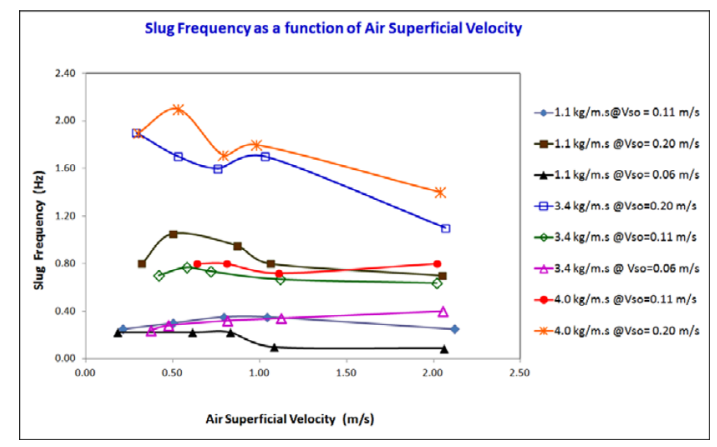

Figure 4: Slug frequency versus air superficial velocity at different oil viscosities and oil superficial velocities.

Figure 4 shows eight cases of slug frequency variations with superficial gas velocity for different oil viscosities and oil superficial liquid velocities. Increasing superficial gas velocity $\left(V_{\mathrm{sg}}\right)$ produces mixed results of constant, increasing and decreasing slug frequency with different degrees of variation for the eight cases illustrated in Fig. 4. When examined individually, the dominant tendency across most of the eight cases is for slug frequency to decrease as superficial gas velocity is increased. There are at least two outlier cases where slug frequency increases with superficial gas velocity. There are remarkable cases where the slug frequency variation with superficial gas velocity is rather complicated. In one such case, slug frequency remains constant at first before declining with increasing superficial gas velocity. In other such cases, the slug frequency initially increases and then decreases with increasing superficial gas velocity. The complexities of the latter cases can be explained by wave mechanics at the gas-liquid interface. An increase in superficial gas velocity leads to an increase in the in situ gas velocity, which generates waves at the gasliquid interface causing slug frequency to rise. However, after a certain superficial gas velocity is reached, the gas phase suppresses liquid hold-up causing the decline of slug frequency thereafter. This is consistent with the findings of a number of researchers such as Gokcal et al. [12] for high viscosity liquid-gas flows and Hernandez-Perez [15] for low viscosity liquid-gas flows.

Moreover, for a specific value of oil superficial velocity $\left(V_{\text {so }}\right)$, increasing the oil viscosity $\left(\mu_{\mathrm{L}}\right)$ has the effect of increasing slug frequency in all eight cases. Similarly, for a specific value of oil viscosity, an increase in liquid superficial velocity also results in an increase in slug frequency. The explanation for this trend is that increasing liquid superficial velocity or liquid viscosity induces an increase in the liquid level within the horizontal pipe section. An increase in liquid level increases the probability for the occurrence of the critical liquid height required for the formation of slug bodies in accordance with the Kelvin-Helmholtz stability phenomenon. In other words, increasing liquid level in the pipe section results in a progressive reduction of the time interval between the formation of slug bodies and therefore, a corresponding increase in slug frequency. The findings reported above are consistent with experimental observations made by Colmenares et al. [1] and Gokcal et al. [12]. It is also clear from Fig. 4 that slug frequency is dependent on liquid viscosity. However, many existing empirical correlations for predicting slug frequency fail to account for the effect of liquid viscosity. 
3.2 Comparison of experimental slug frequency against existing empirical correlations

Experimental slug frequency was compared with predicted results of different empirical correlations for liquid viscosities of $1.1 \mathrm{~kg} / \mathrm{ms}(1100 \mathrm{cP}), 3.4 \mathrm{~kg} / \mathrm{ms}(3400 \mathrm{cP})$ and $4.0 \mathrm{~kg} / \mathrm{ms}$ $(4000 \mathrm{cP})$ for the superficial liquid velocity of $0.11 \mathrm{~m} / \mathrm{s}$.

From Figs 5-7, it is obvious that none of the slug frequency correlations were able to produce predictions of reasonable accuracy. The predicted results tend to diverge from experimental data by several orders of magnitude. Similar trends were noticed for comparisons between experimental and predicted slug frequencies performed for other superficial liquid velocities. Slug frequency correlations developed by Gregory and Scott [4], Heywood and Richardson [6], Nydal [8] and Manolis et al. [7] perform poorly because they all fail to account for the effect of liquid viscosity. These empirical correlations are based on horizontal slug flow tests with gas and low viscosity liquids (typically water or kerosene) where the effects of liquid viscosity are minor.

The slug frequency correlation developed by Gokcal et al. [12] is the only one that took explicit account of the effects of high liquid viscosity by balancing viscous and gravitational forces acting on hydrodynamic slug flow. Therefore, compared with the other correlations, predictions made with the Gokcal et al. [12] correlation is relatively closer to the experimental data. Unfortunately, as seen in Figs 5-7, predictions performed with the Gokcal et al. [12] correlation are insensitive to variation in the gas superficial velocity. In other words, this correlation is unlikely to perform well in conditions where gas flow rate is high enough to exercise strong influence over slug frequency. More importantly, the Gokcal et al. [12]

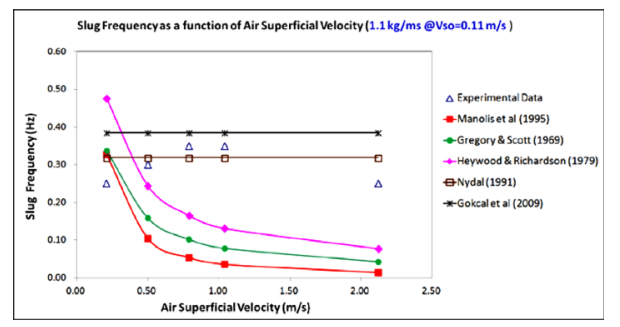

Figure 5: Measured slug frequency versus empirical correlations for $V_{\text {so }}=0.11 \mathrm{~m} / \mathrm{s}$ and $\mu_{L}=1.1 \mathrm{~kg} / \mathrm{ms}$.

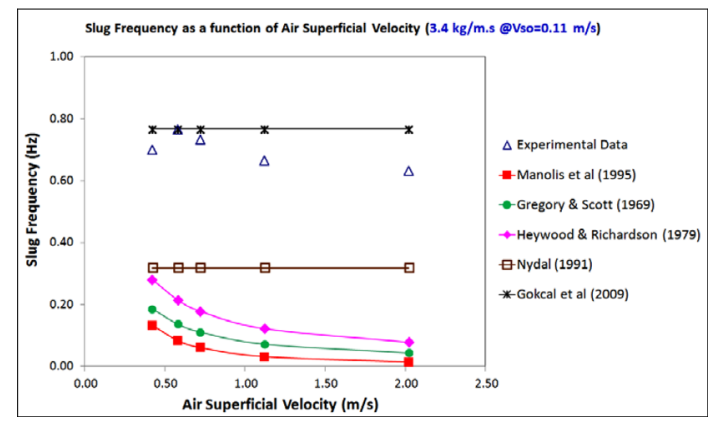

Figure 6: Measured slug frequency versus empirical correlations for $V_{\text {so }}=0.11 \mathrm{~m} / \mathrm{s}$ and $\mu_{L}=3.4 \mathrm{~kg} / \mathrm{ms}$. 


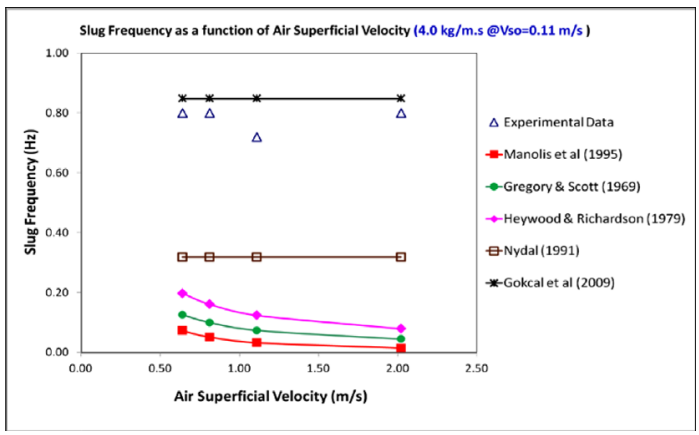

Figure 7: Measured slug frequency versus empirical correlations for $V_{\text {so }}=0.11 \mathrm{~m} / \mathrm{s}$ and $\mu_{L}=4.0 \mathrm{~kg} / \mathrm{ms}$.

correlation is based on high viscosity liquid-gas flow tests with liquid viscosity limited to the range of $0.181 \mathrm{~kg} / \mathrm{ms}(181 \mathrm{cP})-0.589 \mathrm{~kg} / \mathrm{ms}(589 \mathrm{cP})$.

To quantify the discrepancies between experimental data and predicted results in graphs above, Table 2 is produced. Three statistical parameters namely - average percentage relative error (APE), average absolute percentage relative error (AAPE) and standard deviation of relative error - were used to analyse the performance of the empirical correlations.

Table 2: Evaluation of slug frequency correlations using statistics.

\begin{tabular}{lllll}
\hline & $\begin{array}{l}\text { Liquid } \\
\text { viscosity }\end{array}$ & APE & AAPE & $\begin{array}{l}\text { Standard } \\
\text { deviation }\end{array}$ \\
\cline { 2 - 5 } Correlation & $(\mathrm{kg} / \mathrm{ms})$ & $(\%)$ & $(\%)$ & $(\%)$ \\
\hline Manolis et al. [7] & 1.10 & -70.48 & 74.57 & 35.97 \\
& 3.40 & -89.76 & 89.76 & 7.99 \\
& 4.00 & -92.53 & 92.53 & 6.09 \\
\hline Gregory and Scott [4] & 1.10 & -58.52 & 63.60 & 35.55 \\
& 3.40 & -82.90 & 82.90 & 11.34 \\
\hline Heywood and Richardson [6] & 1.10 & -88.44 & 88.44 & 4.63 \\
\hline & 3.40 & -72.79 & 72.79 & 49.39 \\
& 4.00 & -81.88 & 81.88 & 17.71 \\
Nydal [8] & 1.10 & 8.40 & 49.37 & 6.20 \\
\hline Shea et al. [11] & 3.40 & -44.59 & 48.78 & 68.67 \\
& 4.00 & -62.87 & 64.10 & 34.01 \\
& 1.10 & 169.08 & 169.08 & 26.45 \\
\hline Gokcal et al. [12] & 3.40 & 35.54 & 45.14 & 112.34 \\
& 4.00 & 16.50 & 36.11 & 46.55 \\
& 1.10 & 12.20 & 26.89 & 67.40 \\
\hline & 3.40 & 12.33 & 22.35 & 38.52 \\
& 4.00 & 15.86 & 29.80 & 60.29 \\
\hline
\end{tabular}


As seen in Table 2, the correlations either grossly overestimate or underestimate the slug frequency. In the case of the Shea et al. [11] correlation, the error exceeded 100\%, meaning that the predictive results generated from that it were far away from the reality observed in the experiments. Generally, the error seems to increase as liquid viscosity varies from $1.1 \mathrm{~kg} / \mathrm{ms}$ $(1100 \mathrm{cP})$ to $4.0 \mathrm{~kg} / \mathrm{ms}(4000 \mathrm{cP})$. This trend strongly indicates that there is a need for new empirical correlations that can account properly for the effect of extremely high liquid viscosity on oil-gas flows.

\subsection{Effect of flow variables and viscosity on slug body liquid holdup}

Slug body liquid holdup is a closure relationship used in mechanistic models for analysing hydrodynamic slug flow. In this study, experimental slug body holdup is obtained indirectly through probability mass function (PMF) plots of the gas void fraction time series produced from the measured gamma ray attenuation data. Generally, PMF plots generated from gamma attenuation data are used for flow regime identification. A PMF plot with two peaks is an indicator that slug flow is the prevailing flow regime in the measurement pipe section. As illustrated in Fig. 8, the shorter peak is representative of flow of the liquid slug body while the taller peak represents the passage of gas pockets (i.e. film region) through the measurement pipe section.

Gas void fraction values at which the maxima of the peaks in a PMF plot occur directly corresponds to the probabilistic gas void fraction values within the slug body and film region. The corresponding liquid holdup values for the slug body and film region can be calculated from the probabilistic gas void fraction values. To examine the effect of liquid and gas superficial velocities on slug body liquid holdup at different viscosities, Figs 9-11 were plotted.

Figures 9-11 indicate that slug body liquid holdup generally declines as air superficial velocity is increased for all three liquid viscosities used in this study. There is a general caveat the decline in slug body liquid holdup is only apparent at air superficial velocities above $1.0 \mathrm{~m} / \mathrm{s}$, where the rate of gas transfer from the film region to the slug front is high enough to promote significant aeration of the slug body.

As shown in Fig. 12, the slug body liquid holdup increases as liquid viscosity decreases. This viscosity effect becomes apparent at air superficial velocities above $1.0 \mathrm{~m} / \mathrm{s}$. The explanation for the viscosity effect is as follows - the drag force affecting the relative motion between entrained gas bubbles and the surrounding liquid slug reduces with decreasing liquid

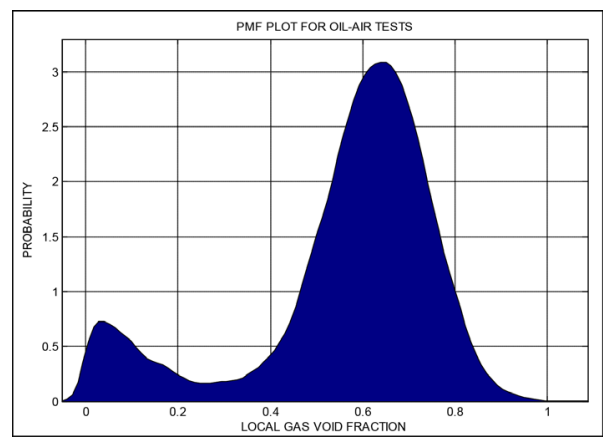

Figure 8: In the PMF plot, the shorter peak is the slug body and the taller peak is the film region. 


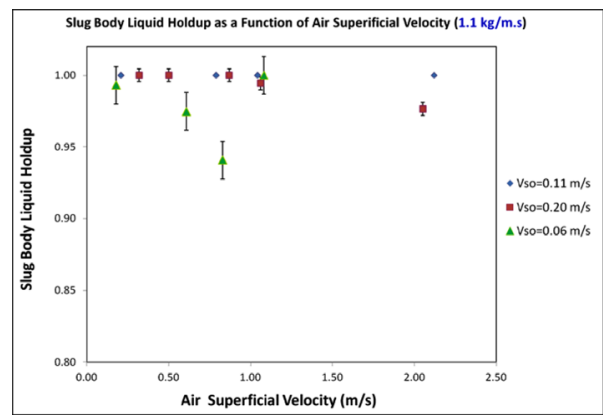

Figure 9: Slug body liquid holdup versus air superficial velocity at different liquid velocities for $\mu_{L}=1.1 \mathrm{~kg} / \mathrm{ms}$.

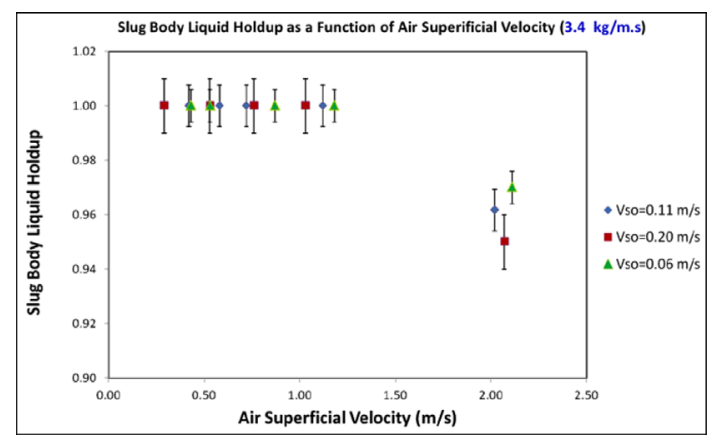

Figure 10: Slug body liquid holdup versus air superficial velocity at different liquid velocities for $\mu_{L}=3.4 \mathrm{~kg} / \mathrm{ms}$.

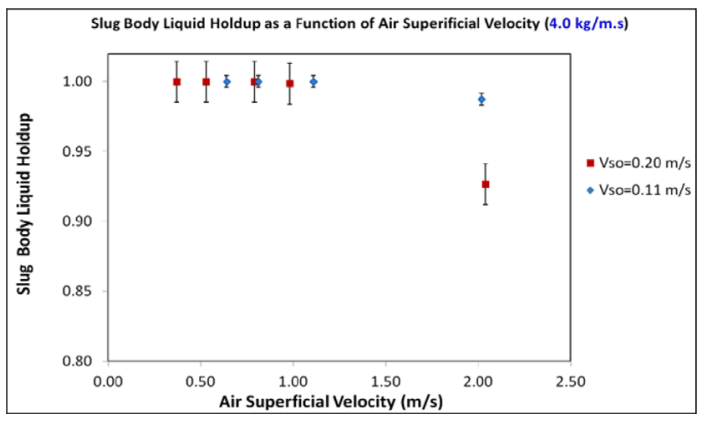

Figure 11: Slug body liquid holdup versus air superficial velocity at different liquid velocities for $\mu_{L}=4.0 \mathrm{~kg} / \mathrm{ms}$.

viscosity. This means that gas is able to separate from liquid at a quicker rate. In other words, the amount of entrained bubbles within the slug body declines with decreasing liquid viscosity, causing an increase in the liquid holdup. Trends similar to what is shown in Fig. 12 were also observed for other liquid superficial velocities. These trends apparently indicate that liquid viscosity has influence over slug body liquid holdup. It should be noted that error bars in Figs 9-12 represent the standard error in the measurement of slug body liquid holdup. 


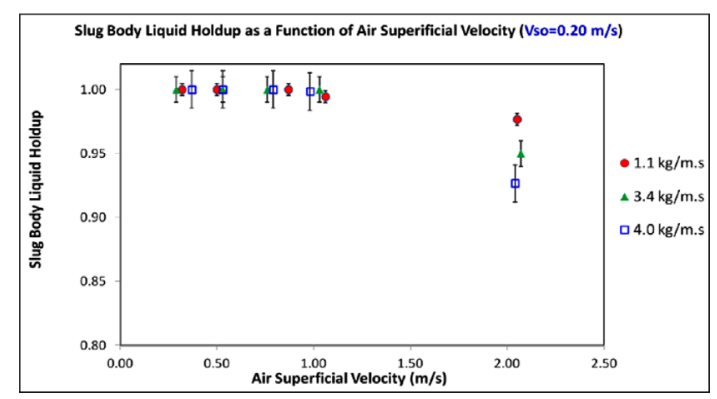

Figure 12: Slug body liquid holdup versus air superficial velocity at various liquid viscosities for $V_{\text {so }}=0.20 \mathrm{~m} / \mathrm{s}$.

Table 3: Evaluation of slug body liquid holdup correlations using statistics.

\begin{tabular}{lllll}
\hline & $\begin{array}{l}\text { Liquid } \\
\text { viscosity }\end{array}$ & APE & AAPE & $\begin{array}{l}\text { Standard } \\
\text { deviation }\end{array}$ \\
\cline { 2 - 5 } Correlation & $(\mathrm{kg} / \mathrm{ms})$ & $(\%)$ & $(\%)$ & $(\%)$ \\
\hline Gregory et al. [5] & 1.10 & -3.90 & 4.24 & 4.20 \\
& 3.40 & -4.94 & 4.94 & 3.13 \\
& 4.00 & -6.53 & 6.53 & 4.83 \\
\hline Abdul-Majeed [9] & 1.10 & 1.31 & 1.37 & 1.80 \\
& 3.40 & 0.86 & 0.86 & 1.00 \\
\hline Gomez et al. [10] & 4.00 & 1.20 & 1.20 & 2.21 \\
\hline Kora et al. [13] & 1.10 & 0.98 & 1.00 & 1.79 \\
& 3.40 & 0.60 & 0.61 & 1.31 \\
& 4.00 & 1.13 & 1.14 & 2.48 \\
\hline
\end{tabular}

3.4 Comparison of experimental slug body liquid holdup against existing empirical correlations

Slug liquid holdup data estimated from PMF plots were compared against empirical correlations developed by Gregory et al. [5], Abdul-Majeed [9], Gomez et al. [10] and Kora et al. [13]. The APE, AAPE and standard deviation of relative error were used to analyse the performance of the empirical correlations.

As seen in Table 3, Gomez et al. [10] and Abdul-Majeed [9] are the best performing correlations when judged by their AAPE values. Across all three liquid viscosities, the predictions produced with those two correlations are closest to experimental data in terms of accuracy. Compared with the others, Gregory et al.'s [5] was the least performing correlation in terms of AAPE values. Nevertheless, for a correlation that fails to account for the effect of liquid viscosity, Gregory et al. [5] performed far better than expected. With the sole exception of Gregory et al. [5], all correlations displayed in Table 3 include a liquid viscosity parameter. However, it should be 
pointed out that these correlations are based on oil-gas experimental data with liquid viscosities much lower than the $1.1 \mathrm{~kg} / \mathrm{ms}(1100 \mathrm{cP})$ to $4.0 \mathrm{~kg} / \mathrm{ms}(4000 \mathrm{cP})$ range under investigation.

\section{DEVELOPMENT OF A NEW SLUG FREQUENCY CORRELATION FOR HIGH VISCOSITY LIQUID-GAS FLOWS}

Using Buckingham Pi Theorem, four dimensionless groups were generated from physical quantities that are known to influence slug frequency (Freq) namely - mixture viscosity $\left(\mu_{\mathrm{M}}\right)$, gas density $\left(\rho_{\mathrm{G}}\right)$, liquid density $\left(\rho_{L}\right)$, mixture velocity $\left(V_{\mathrm{M}}\right)$, superficial liquid velocity $\left(V_{\mathrm{SL}}\right)$, acceleration due to gravity $(g)$ and pipe diameter $(D)$.

Mathematically,

$$
\text { Freq }=\Psi\left(V_{S L} ; V_{M} ; g ; D ; \rho_{L} ; \rho_{G} ; \mu_{M}\right)
$$

Four dimensionless groups were obtained from eqn (3) as illustrated in eqn (4):

$$
\left(\frac{\text { Freq } \times D}{V_{M}}\right)=\Psi\left(\frac{V_{S L}}{V_{M}} ; \mathrm{Fr}_{\mathrm{M}} ; \mathrm{Re}_{\mathrm{M}}\right)
$$

where

Mixture Froude number $\left(\mathrm{Fr}_{\mathrm{M}}\right)=\frac{V_{M}}{\sqrt{g D}}$

Mixture Reynolds number $\left(\operatorname{Re}_{\mathrm{M}}\right)=\frac{\rho_{M} V_{M} D}{\mu_{\mathrm{M}}}$

Dimensionless slug frequency (i.e. Strouhal number) $=\left(\frac{F r e q \times D}{V_{M}}\right)$

Input liquid volume fraction $=\frac{V_{S L}}{V_{M}}$

$\Psi=$ Function symbol

For ease of calculation, a mixture density was replaced with liquid density in the equation for mixture Reynolds Number. This is justifiable since mixture kinematic viscosity $\left(\mu_{M} / \rho_{M}\right)$ was found to be approximately equal to the liquid kinematic viscosity $\left(\mu_{\mathrm{L}} / \rho_{\mathrm{L}}\right)$ for over a range of flow conditions:

$$
\operatorname{Re}_{\mathrm{M}}=\frac{\rho_{M} V_{M} D}{\mu_{M}} \approx \frac{\rho_{L} V_{M} D}{\mu_{L}}
$$

Replacing mixture density with liquid density means that there is no need to introduce a separate correlation to obtain in situ gas void fraction and liquid holdup values that are necessary for calculating mixture density and mixture viscosity.

The standard mathematical definition for Froude Number in eqn (4) was replaced with the definition for densimetric Froude number below:

$$
F r_{M}=V_{M} \times \sqrt{\frac{\rho_{L}}{g D\left(\rho_{L}-\rho_{G}\right)}}
$$

Across different liquid viscosities, Strouhal number correlated well with all the other dimensionless groups in eqn (4) as illustrated in Figs 13-15. Even though Figs 13-15 were 


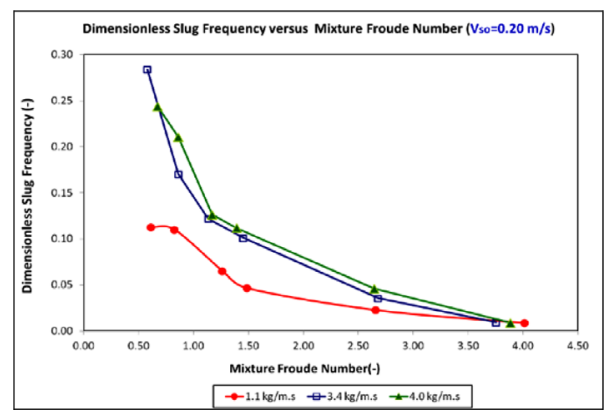

Figure 13: Strouhal number versus mixture Froude number at various liquid viscosities for $V_{\text {so }}=0.2 \mathrm{~m} / \mathrm{s}$.

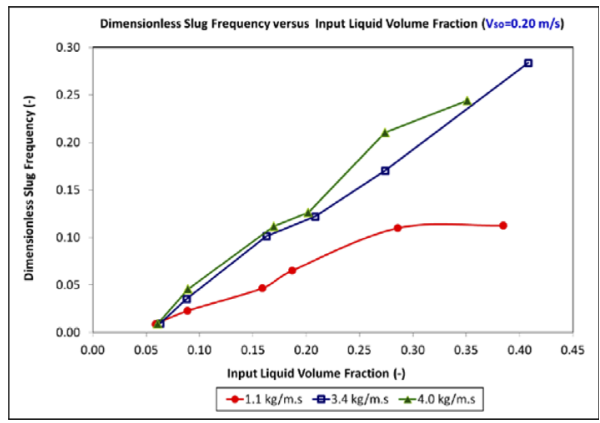

Figure 14: Strouhal number versus input liquid fraction at various liquid viscosities for $V_{\text {so }}=0.2 \mathrm{~m} / \mathrm{s}$.

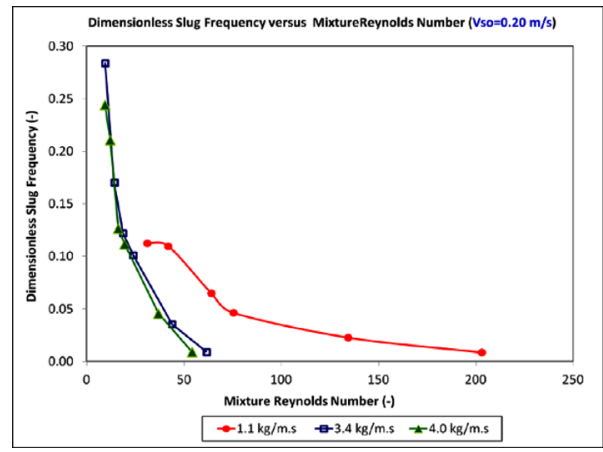

Figure 15: Strouhal number versus mixture Reynolds number at various liquid viscosities for $V_{\text {so }}=0.2 \mathrm{~m} / \mathrm{s}$.

just for $V_{\mathrm{so}}=0.20 \mathrm{~m} / \mathrm{s}$, similar trends were observed for the other two superficial oil velocities namely: 0.06 and $0.11 \mathrm{~m} / \mathrm{s}$.

Judging from the appearance of the curves Figs 13-15, it was hypothesized that the slug frequency correlation will follow the nonlinear format below:

$$
\left(\frac{\text { Freq } \times D}{V_{M}}\right)=\beta\left[\left(\frac{V_{S L}}{V_{M}}\right)^{\mathrm{a}}\left(\mathrm{Fr}_{M}\right)^{\mathrm{b}}\left(\operatorname{Re}_{M}\right)^{\mathrm{c}}\right]
$$


Equation (7) was linearized using the natural logarithmic function:

$$
\operatorname{Ln}\left(\frac{F r e q \times D}{V_{M}}\right)=\operatorname{Ln}(\beta)+\mathrm{a} \operatorname{Ln}\left(\frac{V_{S L}}{V_{M}}\right)+\mathrm{b} \operatorname{Ln}\left(F r_{M}\right)+\mathrm{c} \operatorname{Ln}\left(\operatorname{Re}_{M}\right)
$$

Multiple linear regression analysis was performed in eqn (8). As depicted in Table 4, the following intercept and the coefficients of the logarithmic equation were obtained: ' $\operatorname{Ln}(\beta)$ ' $=$ $1.284 ;$ ' $a$ ' $=1.299$; ' $b$ ' $=0.497$ and ' $c$ ' $=-0.531$.

Taking anti-logarithm on both sides of eqn (8) and then fitting in the regression coefficients gives

$$
\left(\frac{\text { Freq } \times D}{V_{M}}\right)=3.6102\left[\left(\frac{V_{S L}}{V_{M}}\right)^{1.299} F r_{M}^{0.497} \mathrm{Re}_{M}^{-0.531}\right]
$$

Re-arranging eqn (9) to make slug frequency the subject of the formula:

$$
\text { Freq }=\left(\frac{3.6102}{D}\right)\left(\frac{V_{S L}^{1.299}}{V_{M}^{0.299}}\right)\left(\frac{F r_{M}^{0.497}}{\operatorname{Re}_{M}^{0.531}}\right)
$$

Equation (10) is the new slug frequency correlation (Freq) developed on the basis of data obtained from high viscosity oil-gas experiments performed for three liquid viscosities (1.1, 3.4 and $4.0 \mathrm{~kg} / \mathrm{ms}$ ) at the flow conditions specified in Table 1.

\subsection{Statistical evaluation of the proposed empirical correlation}

A plethora of statistical parameters were used to evaluate the reliability of the regression coefficients and the empirical model as a whole. These parameters are displayed in Tables 4 and 5. Residual plots represented by Figs 16(a)-(d) were also used to illustrate the quality of the newly developed empirical model.

Table 4: Overall statistical evaluation of the slug frequency correlation.

\begin{tabular}{|c|c|c|c|c|c|c|}
\hline Variable & $\begin{array}{l}\text { Regression } \\
\text { Coefficient }\end{array}$ & $\begin{array}{l}\text { Standard } \\
\text { error }\end{array}$ & T-statistics & P-values & $\begin{array}{l}\text { Lower } 95 \% \\
\text { Confidence } \\
\text { interval }\end{array}$ & $\begin{array}{l}\text { Upper } 95 \% \\
\text { Confidence } \\
\text { interval }\end{array}$ \\
\hline Intercept & $\operatorname{Ln}(\beta)=1.284$ & 0.371 & 3.458 & 0.001 & 0.534 & 2.034 \\
\hline $\operatorname{Ln}\left(\mathrm{V}_{\mathrm{SL}} / \mathrm{V}_{\mathrm{M}}\right)$ & $a=1.299$ & 0.121 & 10.718 & 0.000 & 1.054 & 1.544 \\
\hline $\operatorname{Ln}\left(\mathrm{Fr}_{\mathrm{M}}\right)$ & $b=0.497$ & 0.149 & 3.334 & 0.002 & 0.196 & 0.798 \\
\hline $\operatorname{Ln}\left(\operatorname{Re}_{M}\right)$ & $c=-0.531$ & 0.093 & -5.686 & 0.000 & -0.720 & -0.342 \\
\hline
\end{tabular}

\begin{tabular}{llllll}
\hline Model dF & Error dF & SSE & MSE & $\mathrm{R}^{2}$ & Adjusted R $^{2}$ \\
\hline 3 & 40 & 5.002 & 0.125 & 0.893 & 0.885 \\
\hline
\end{tabular}

Table 5: Statistical evaluation of the regression coefficients in the slug frequency correlation. 
In Table 4, the degree of freedom for the empirical model ('model dF') is 3, reflecting the fact that three independent variables - ' $\mathrm{Re}_{\mathrm{M}}$; ' $\mathrm{Fr}_{\mathrm{M}}$ ' and ' $\mathrm{V}_{\mathrm{SL}} / \mathrm{V}_{\mathrm{M}}$ ' - were used to develop the new slug frequency correlation. The sum of squares error (SSE) quantifies the discrepancy between the actual values of the dependent variable and the predictions performed with the empirical slug frequency model. The mean squared error (MSE) quantifies the degree of the scatter of the data around the idealistic straight line in the graph.

The ' $R^{2}$ ' value (also called 'coefficient of determination') is a measure of the fraction of the variation in the dependent variable (i.e. Strouhal Number) that can be predicted by the independent variables - Reynolds Number, Froude number and the input liquid volume fraction. Generally, the coefficient of determination ( ' $R{ }^{2}$ ') ranges from 0.0 to 1 . 0 . The ' $R{ }^{2}$ ' value is 0.0 when none of the variation in the dependent variable can be predicted by the independent variables - meaning that there is no linear relationship between the dependent and independent variables. Conversely, ' $R{ }^{2}$ ' is 1.0 , when all the variations in the dependent variable can be predicted exactly by the independent variables. The closer a ' $R$ ', value is to unity, the higher the accuracy of an empirical correlation. In Table 4 , the ' $R$ ' ' value is 0.893 . This means that $89.3 \%$ of the variation in the dimensionless slug frequency can be explained by the independent variables. In other words, the proposed slug frequency correlation is a good regression model.

Without accounting for the number of independent variables present, the ' $R{ }^{2}$ ' value quantifies how well an empirical model fits test data in a regression graph. Since empirical models with several independent variables can 'twist' and 'bend' to come nearer to the data points in the graph, an inflated ' $R{ }^{2}$ ' value is always a possibility in multiple linear regression analyses.

The adjusted ' $R$ ' ' value tackles this problem by accounting for the number of independent variables present an empirical model. The closer an adjusted ' $R{ }^{2}$ ' value is to unity, the higher the accuracy of the empirical model. In Table 3 , the adjusted ' $R^{2}$ ' value for the proposed slug frequency correlation is 0.885 .

In Table 5, the standard error of the independent variables quantifies the scatter of each coefficient value around its mean. The standard error - which is analogous to standard deviation is used to calculate the confidence intervals. ' $P$-value' is the probability that an independent variable (i.e. dimensionless group) plays no role in the prediction of slug frequency with the proposed empirical model. A ' $P$-value' of 0.05 (i.e. $5 \%$ ) or less is universally accepted as the significance level at which it is okay to reject the null hypothesis that an independent variable is not having any effect on the dependent variable. As seen in Table 5, the $P$-values were below 0.05 ; therefore, the null hypothesis was rejected. In other words, all the independent variables in the empirical model have significant effect on dimensionless slug frequency.

Though not as robust as the statistical parameters in Tables 4 and 5, residual plots are also used to examine the overall suitability of empirical models. The plots check if there are any correlation between the variables and the residual values. If there is an obvious correlation between the residual values and the variables (e.g. the residual values increase as a variable is increasing), then the empirical model is unreliable. However, if the residual values appear random and do not indicate any obvious correlation between the residual values and the variables, then the empirical model is deemed reliable. Given the randomness of the residual values in Figs 16(a)-(d), it is clear that the slug frequency model is reliable.

4.2 Comparison of proposed and existing slug frequency correlations against high viscosity experimental data

As part of the process of model validation, the newly developed empirical correlation was compared against independent high viscosity oil-gas data. Existing correlations in literature 


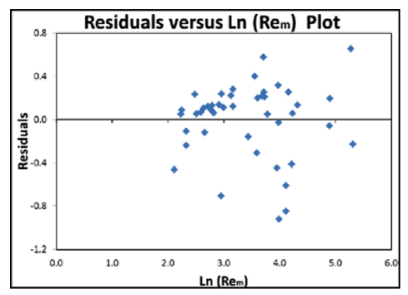

(a)

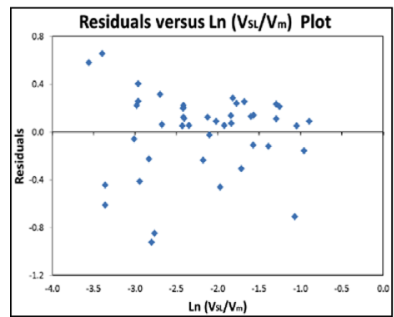

(c)

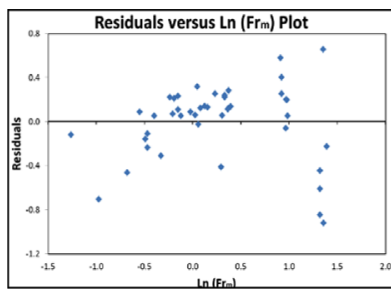

(b)

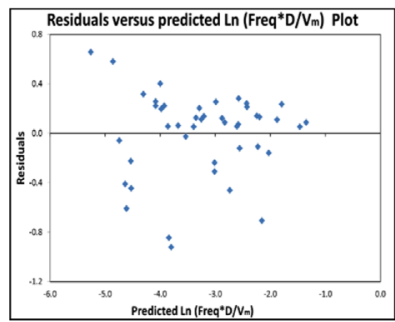

(d)

Figure 16: The plots indicate no obvious correlation between residual values and the logarithms of (a) mixture Reynolds number; (b) mixture Froude number; (c) liquid fraction and (d) predicted Strouhal number.

Table 6: Performance evaluation of proposed and existing correlations using statistics.

\begin{tabular}{lcccc}
\hline & $\begin{array}{c}\text { Liquid } \\
\text { viscosity }\end{array}$ & APE & AAE & $\begin{array}{c}\text { Standard } \\
\text { deviation }\end{array}$ \\
\cline { 2 - 5 } Correlation & $(\mathrm{kg} / \mathrm{ms})$ & $(\%)$ & $(\mathrm{Hz})$ & $(\%)$ \\
\hline Manolis et al. [7] & 2.50 & -82.49 & 0.370 & 16.66 \\
Gregory and Scott [4] & 2.50 & -73.33 & -0.408 & 18.19 \\
Heywood and Richardson [6] & 2.50 & -58.76 & -0.335 & 25.56 \\
Nydal [8] & 2.50 & -37.81 & -0.221 & 16.22 \\
Shea et al. [11] & 2.50 & 75.70 & 0.360 & 45.83 \\
Gokcal et al. [12] & 2.50 & 24.14 & 0.096 & 32.38 \\
Newly developed correlation & 2.50 & 15.55 & 0.048 & 38.54 \\
\hline
\end{tabular}

were also tested against the independent data to compare their performance to the newly developed correlation.

The independent data set was obtained from the 3-inch. CHOPS test rig for liquid viscosity of $2.5 \mathrm{~kg} / \mathrm{ms}(2500 \mathrm{cP})$ at $V_{\mathrm{so}}=0.11 \mathrm{~m} / \mathrm{s}$ and was not included in the process of developing the new empirical correlation. As stated earlier, the empirical correlation was developed solely from the combined oil-gas data sets for $1.1 \mathrm{~kg} / \mathrm{ms}(1100 \mathrm{cP}), 3.4 \mathrm{~kg} / \mathrm{ms}(3400 \mathrm{cP})$ and $4.0 \mathrm{~kg} / \mathrm{ms}(4000 \mathrm{cP})$.

Using the independent data set as standard reference, three statistical parameters namely average percentage relative error (APE), average actual error (AAE) and standard deviation of relative error - were used to analyse the predictive performance of all the empirical correlations as shown in Table 6. 
From Table 6, it is clear that the correlations either overestimate or underestimate the slug frequency. Nevertheless, the newly developed slug frequency correlation outperformed the published correlations when judged by their APE and AAE values. In other words, with a relative error of $15.55 \%$, the predictions of the newly developed slug frequency correlation are closest to experimental data in terms of accuracy. However, the standard deviation of the newly slug frequency correlation was quite high in comparison to the other correlations.

\section{CONCLUSION}

The effects of viscosity and flow variables on slug parameters were investigated experimentally. It was found that increasing either oil viscosity or oil superficial velocity caused a corresponding increase in slug frequency. Increasing gas superficial velocity produced mixed results of constant, increasing and decreasing slug frequency with different degrees of variation. Despite these mixed results, the dominant tendency is for slug frequency to decrease as superficial gas velocity is increased at the different oil viscosities and oil superficial velocities used in this study. Generally, slug body liquid hold-up decreases with increasing air superficial velocity. For a given superficial liquid velocity, slug body liquid hold-up increases as liquid viscosity decreases. In most experiments conducted for this study, this viscosity effect becomes apparent at air superficial velocities above $1.0 \mathrm{~m} / \mathrm{s}$. Empirical correlations published in open literature were compared against measured high viscosity slug flow parameters. Slug body liquid hold-up correlations produced predictions in close agreement with high viscosity experimental data. On the other hand, none of the slug frequency correlations tested against experimental slug frequency data was able to produce predictions of reasonable accuracy. Generally, the errors in the slug frequency predictions increase as liquid viscosity varies from $1.1 \mathrm{~kg} / \mathrm{ms}(1100 \mathrm{cP})$ to $4.0 \mathrm{~kg} / \mathrm{ms}(4000 \mathrm{cP})$. This trend strongly indicated a need for a new slug frequency correlation that can account properly for effect of extremely high liquid viscosity on oil-gas flows. On the basis of dimensional analysis and multiple linear regression analysis, a new empirical slug frequency correlation was developed. This newly developed slug frequency correlation was compared against an independent experimental data set. The comparison indicated that the new empirical correlation performed better than existing correlations in terms of predicting slug frequency for high viscosity liquid-gas flows. This means that the new correlation can significantly improve the accuracy of mechanistic models for analysing hydrodynamic slugging in horizontal high viscosity liquid-gas production pipelines.

\section{ACKNOWLEDGEMENTS}

The author acknowledges The Department of Offshore, Process \& Energy Engineering at Cranfield University, UK for provision of laboratory facilities he used to perform experiments featured in this paper. The author thanks Neftemer Ltd for providing the gamma densitometer used in all the oil-gas experiments. Additionally, the author thanks all his research colleagues who helped in getting the test rig to run smoothly during experiments.

\section{REFERENCES}

[1] Colmenares, J., Ortega, P., Padrino, J. \& Trallero, J.L., Slug flow model for the prediction of pressure drop for high viscosity oils in a horizontal pipeline, SPE International Thermal Operations and Heavy Oil Symposium, Margarita Island, Venezuela, 2001. doi: http://dx.doi.org/10.2523/71111-ms 
[2] Gokcal, B., Wang, Q., Zhang, H.Q. \& Sarica, C., Effects of high oil viscosity on oil/gas flow behaviour in horizontal pipes, SPE Annual Technical Conference and Exhibition, San Antonio, Texas, USA, 2006. doi: http://dx.doi.org/10.2523/102727-ms

[3] Matsubara, H. \& Naito, K., Effect of liquid viscosity on flow patterns of gas-liquid two-phase flow in a horizontal pipe. International Journal of Multiphase Flow, 37(10), pp. 1277-1281, 2011. doi: http://dx.doi.org/10.1016/j.ijmultiphaseflow.2011.08.001

[4] Gregory, G.A. \& Scott, D.S., Correlation of liquid slug velocity and frequency in horizontal co-current gas-liquid slug flow. AIChE Journal, 15(6), pp. 933-935, 1969. doi: http://dx.doi.org/10.1002/aic.690150623

[5] Gregory, G.A., Nicholson, M.K. \& Aziz, K., Correlation of the liquid volume fraction in the slug for horizontal gas-liquid slug flow. International Journal of Multiphase Flow, 4, pp. 33-39, 1978. doi: http://dx.doi.org/10.1016/0301-9322(78)90023-X

[6] Heywood, N.I. \& Richardson, J.F., Slug flow of air-water mixtures in a horizontal pipe: determination of liquid hold-up by gamma-ray absorption. Chemical Engineering Science, 34, pp. 17-30, 1979. doi: http://dx.doi.org/10.1016/0009-2509(79)85174-x

[7] Manolis, I., Meendes-Tatis, M. \& Hewitt, G., The effect of pressure on slug frequency in two-phase horizontal flow, 2nd International Conference on Multiphase Flow, Kyoto, Japan, 1995. doi: http://dx.doi.org/10.1016/b978-0-444-81811-9.50035-4

[8] Nydal, O.J., An experimental investigation of slug flow. PhD Thesis, University of Oslo, Norway, 1991.

[9] Abdul-Majeed, G.H., Liquid slug holdup in horizontal and slightly inclined two-phase slug flow. Journal of Petroleum Science and Engineering, 27, pp. 27-32, 2000. doi: http://dx.doi.org/10.1016/s0920-4105(99)00056-X

[10] Gomez, L.E., Shoham, O. \& Taitel, Y., Prediction of slug liquid holdup: horizontal to upward vertical flow. International Journal of Multiphase Flow, 26, pp. 517-521, 2000. doi: http://dx.doi.org/10.1016/s0301-9322(99)00025-7

[11] Shea, R.H., Eidesmoen, H., Nordsveen, M., Rasmussen, J., Xu, Z.G. \& Nossen, J., Slug frequency prediction method comparisons, Proceedings of the 4th North American Conference on Multiphase Technology, pp. 227-237, 2004.

[12] Gokcal, B., Al-Sarkhi, A.S., Sarica, C. \& Al-Safran, E.M., Prediction of slug frequency for high-viscosity oils in horizontal pipes, SPE European Formation Damage Conference, New Orleans, Louisiana, USA, 2009. doi: http://dx.doi.org/10.2118/124057-ms

[13] Kora, C., Sarica, C., Zhang, H.Q., Al-Sarkhi, A. \& Al-Safran, E.M., Effects of high oil viscosity on slug liquid holdup in horizontal pipes, SPE Canadian Unconventional Resources Conference, Calgary, Alberta, Canada, 2011. doi: http://dx.doi. org/10.2118/146954-ms

[14] Okezue, C.N., Application of the gamma radiation method in analysing the effect of liquid viscosity and flow variables on slug frequency in high viscosity oil-gas horizontal flow. WIT Transactions on Engineering Sciences, 79, pp. 447-461, 2013, ISSN 17433533. doi: http://dx.doi.org/10.2495/mpf130371

[15] Hernandez-Perez, V., Gas-liquid two-phase flow in inclined pipes. PhD Thesis, University of Nottingham, United Kingdom, 2007. 